\title{
Effects of Additives and Sintering Time on the Microstructure of Ni-Zn Ferrite and Its Electrical and Magnetic Properties
}

\author{
Abdollah Hajalilou, ${ }^{1}$ Mansor Hashim, ${ }^{1}$ and Halimah Mohamed Kamari ${ }^{2}$ \\ ${ }^{1}$ Materials Synthesis and Characterization Laboratory, Institute of Advanced Technology (ITMA), Universiti Putra Malaysia (UPM), \\ 43400 Serdang, Selangor, Malaysia \\ ${ }^{2}$ Physics Department, Universiti Putra Malaysia (UPM), 43400 Serdang, Selangor, Malaysia
}

Correspondence should be addressed to Abdollah Hajalilou; e.hajalilou@yahoo.com

Received 28 August 2014; Revised 1 December 2014; Accepted 4 December 2014; Published 24 December 2014

Academic Editor: You Song

\begin{abstract}
Copyright (C) 2014 Abdollah Hajalilou et al. This is an open access article distributed under the Creative Commons Attribution License, which permits unrestricted use, distribution, and reproduction in any medium, provided the original work is properly cited.

This work aims to investigate the relationship between the microstructure of $\mathrm{Ni}-\mathrm{Zn}$ ferrite and its electrical and magnetic properties in the presence and absence of as small amounts as $0.12 \%$ of $0.4 \mathrm{CaO}+0.8 \mathrm{SiO}_{2}$ over different sintering times. The X-ray diffraction pattern showed a single spinel phase formation in all the samples. The results indicate that grain growth occurred by increasing sintering time from 15 to $270 \mathrm{~min}$ in the two types of samples prepared in this study although it was greatly impeded by the additive oxides. Moreover, the oxides increase the resistivity of the ferrite and decrease its zinc loss. Magnetic properties such as induction magnetization $\left(B_{S}\right)$ and saturation magnetization $\left(M_{S}\right)$ decreased in the presence of the additives while its coercivity $\left(H_{C}\right)$ increased. Finally, the density of the samples was observed to increase with increasing sintering time in both types of the samples but with a higher value in the samples with no additives.
\end{abstract}

\section{Introduction}

Soft magnetic spinel Ni-Zn ferrite materials are of great interest for their unique magnetic and electrical properties, especially their low current losses, which justify their wide applications in electrical industries [1,2]. Different methods have been developed for preparing these materials $[3,4]$. Their magnetic and electrical behaviors strongly depend on their chemical composition and microstructure [1,57]. Several studies have focused on the variation of $\mathrm{Ni}-\mathrm{Zn}$ ferrite microstructure by changing the $\mathrm{Zn}$ or Ni content and sintering conditions $[1,8]$. From an industrial point of view, a practical advantage exists when electrical resistivity of ferrites increases significantly with the addition of minor amounts of $\mathrm{CaO}$ or $\mathrm{CaO}$ and $\mathrm{SiO}_{2}$ [9]. Moreover, $\mathrm{CaO}, \mathrm{SiO}_{2}$, or both are generally added to spinel ferrites to achieve such improved magnetic properties as enhanced initial permeability and reduced eddy current losses $[10,11]$. The doped ferrites with $\mathrm{SiO}_{2}+\mathrm{CaO}$ would have an inhomogeneous dielectric structure which consists of electrically conducting grains and insulating layers separating the grains. Furthermore, a radioautography study indicated that $\mathrm{CaO}$ and $\mathrm{SiO}_{2}$ were highly localized at the grain boundaries to form insulating layers. The substance present at grain boundaries was considered to have a composition of $\left(\mathrm{Ca}_{1-x} \mathrm{Si}_{x} \mathrm{O}_{3}\right)_{1-y}$ (ferrite) ${ }_{y}$. A possible mechanism of the formation of this substance is that a liquid phase containing $\mathrm{CaO}$ and $\mathrm{SiO}_{2}$ may form at the grain boundaries at the sintering temperature [9]. The present study attempts to investigate the effects of the sintering time and $0.4 \mathrm{CaO}+0.8 \mathrm{SiO}_{2}$ used as additives on the microstructure as well as the magnetic and electrical properties of the $\mathrm{Ni}_{0.36} \mathrm{Zn}_{0.64} \mathrm{Fe}_{2} \mathrm{O}_{4}$ ferrite.

\section{Methodology}

$\mathrm{Zn}, \mathrm{NiO}, \mathrm{Fe}_{2} \mathrm{O}_{3}, \mathrm{SiO}_{2}$, and $\mathrm{CaO}$ powders were purchased from Alfa Asser and used without further purification. Two types of samples were prepared for the purposes of this study, one comprising $\mathrm{Zn}, \mathrm{NiO}$, and $\mathrm{Fe}_{2} \mathrm{O}_{3}$ and named "additivefree samples" and the other prepared with the same powders 


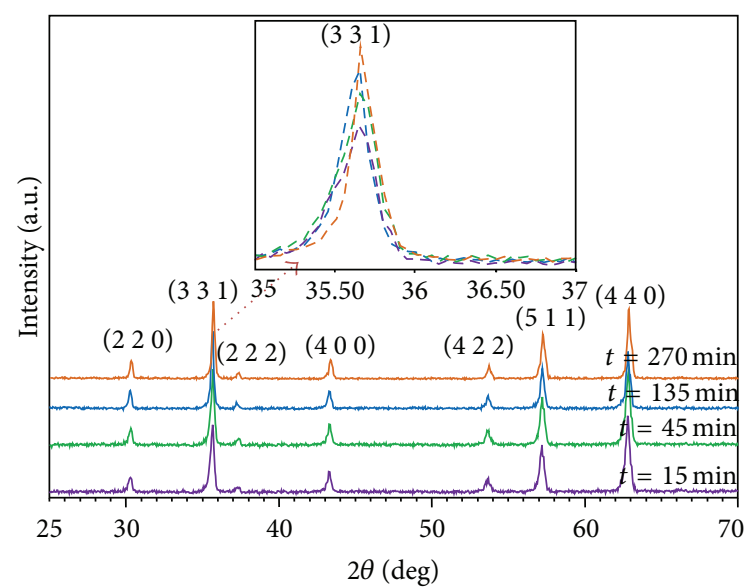

(a)

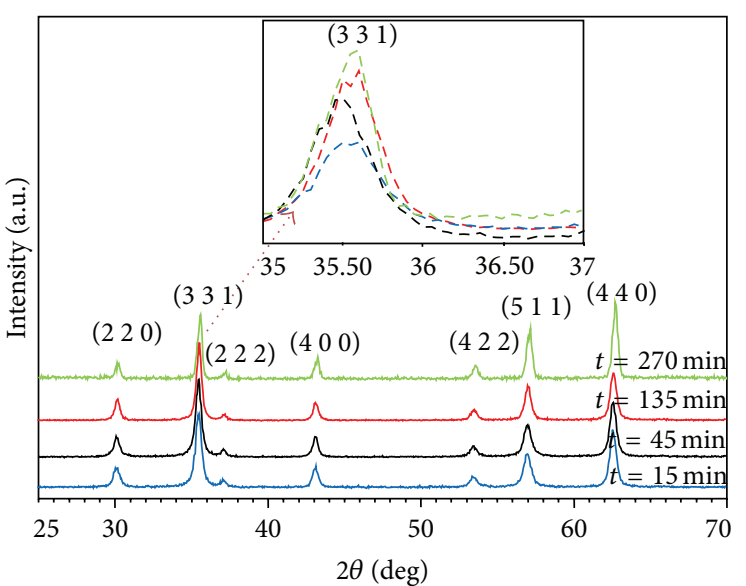

(b)

FIGURE 1: X-ray diffraction patterns for (a) $\mathrm{Ni}_{0.36} \mathrm{Zn}_{0.64} \mathrm{Fe}_{2} \mathrm{O}_{4}$ ferrite without additive and (b) with $0.12\left(0.4 \mathrm{CaO}+0.8 \mathrm{SiO}{ }_{2}\right)$ additive at different sintering times.

with $0.12 \%$ of $0.4 \mathrm{CaO}+0.8 \mathrm{SiO}_{2}$ added and named "additivecontaining samples." In each case, the powders were weighed and mixed based on molar masses in the two different compositions of $\mathrm{Ni}_{0.36} \mathrm{Zn}_{0.64} \mathrm{Fe}_{2} \mathrm{O}_{4}$ and $\mathrm{Ni}_{0.36} \mathrm{Zn}_{0.64} \mathrm{Fe}_{2} \mathrm{O}_{4}+$ $0.12\left(0.4 \mathrm{CaO}+0.8 \mathrm{SiO}_{2}\right)$. The samples thus prepared were mechanically alloyed by high-energy ball milling for $12 \mathrm{~h}$ with a ball-to-powder weight ratio of $20: 1$ maintained throughout. The milled powders were then blended with PVA (1\%) at a ratio of $1: 1$ and dried under an infrared spotlight. A mold, with an outer diameter of $20 \mathrm{~mm}$ and an inner diameter of $10 \mathrm{~mm}$, was used to make toroid shape samples under 4 tons of pressure. Finally, the samples were sintered at $1200^{\circ} \mathrm{C}$ for $15,45,135$, and $270 \mathrm{~min}$.

Structural and phase evaluation of the sintered samples was studied by an X-ray diffraction spectrometer at a diffraction angular range of $2 \theta=25-70^{\circ}$ and by using $\mathrm{Cu} \mathrm{K} \alpha$ (wave length $(\lambda)=0.154 \mathrm{~nm}$ ).

Field emission scanning electron microscopy (FeSEM) using an FEI NOVA NanoSEM 230 machine was used to study the microstructure and grain distribution. The mean grain size of the sintered body samples was calculated by the linear intercept technique over 200 grains. Density was measured based on the Archimedes principle using water as the fluid medium. The electrical resistance $(R)$ was carried out using a Keithley 6485 Picoammeter. The samples were placed between parallel plates and attached to the instrument. A current $(I=V / R)$ passed through the sample by a conducting metallic contact deposited at each sample's toroidal surface. For a better electrical connection, a silver paste was deposited on the surface after a smooth polish using silicon carbide paper. The sample's resistivity was measured using the following relation:

$$
\rho=\left(\frac{A R}{l}\right) \Omega \mathrm{cm},
$$

with $A, l$, and $R$ being the sample's cross-section area, thickness, and electrical resistance.

Magnetic properties were measured using a vibrating sample magnetometer (VSM) and the $M-H$ hysteresis loops were derived to determine the saturation magnetization $\left(M_{S}\right)$ and coercivity $\left(H_{C}\right)$. Samples used for VSM measurement were broken up into small pieces and a mass of $0.03 \mathrm{~g}$ was weighed for each sample. The $B-H$ hysteresis loop of the bulk samples was studied using a MATS-2010SD Static Hysteresisgraph.

\section{Results and Discussion}

The X-ray diffraction patterns for the sintered samples (for both cases) are shown in Figure 1. The XRD results showed that a single spinel phase was formed in all the samples. This indicates that the energy provided from the high-energy ball milling with subsequent sintering was enough to produce a desired single spinel phase. Remarkable changes observed in both types of the samples were the increase of intensity of the samples with increasing the sintering time. This indicates the crystallite growth with increase in the sintering temperature. This is highlighted for a major peak of the spinel phase which confirms this behavior. By comparing the peaks intensity in the two types of the samples, it revealed that the peak width of the samples with additives was more broadened than that of the additive-free samples. From this point, the crystallite growth was hindered in the presence of $\mathrm{SiO}_{2}$ and $\mathrm{CaO}$.

The FeSEM images with histograms of grain distribution, as shown in Figure 2, and the data in Table 1 reveal that grain size grew continuously in both types of samples with increasing sintering time. The dominant grain size distribution in samples sintered for 15 minutes in the presence of the additives ranged over $0.2-0.4 \mu \mathrm{m}$, with the average being $0.350 \mu \mathrm{m}$. Increasing sintering time to $270 \mathrm{~min}$ led to the rise of the dominant grain size distribution to a range of $0.2-1 \mu \mathrm{m}$ with its average being $0.696 \mu \mathrm{m}$. In the case of additive-free samples, not only grain growth did occur with increasing sintering time but larger grains were also observed compared to the samples containing the additives. Moreover, the additive-free samples sintered for $15 \mathrm{~min}$ recorded a dominant grain size of 0.2 to $0.6 \mu \mathrm{m}$, with an average value 

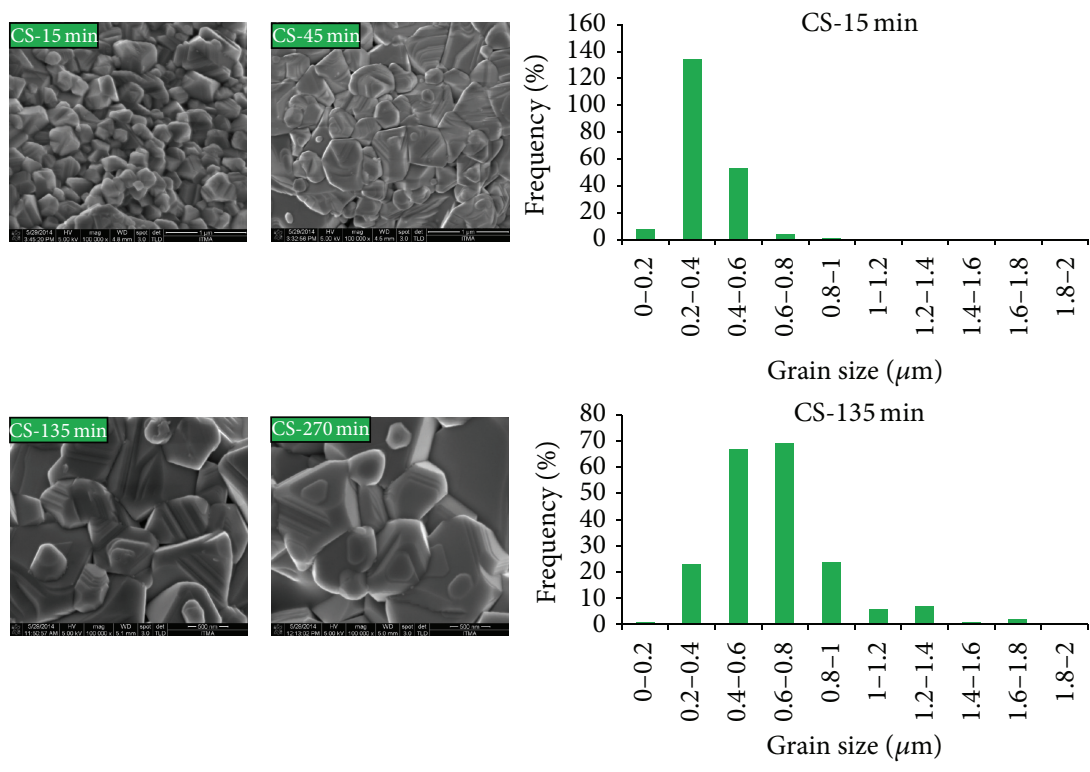

CS-135 min
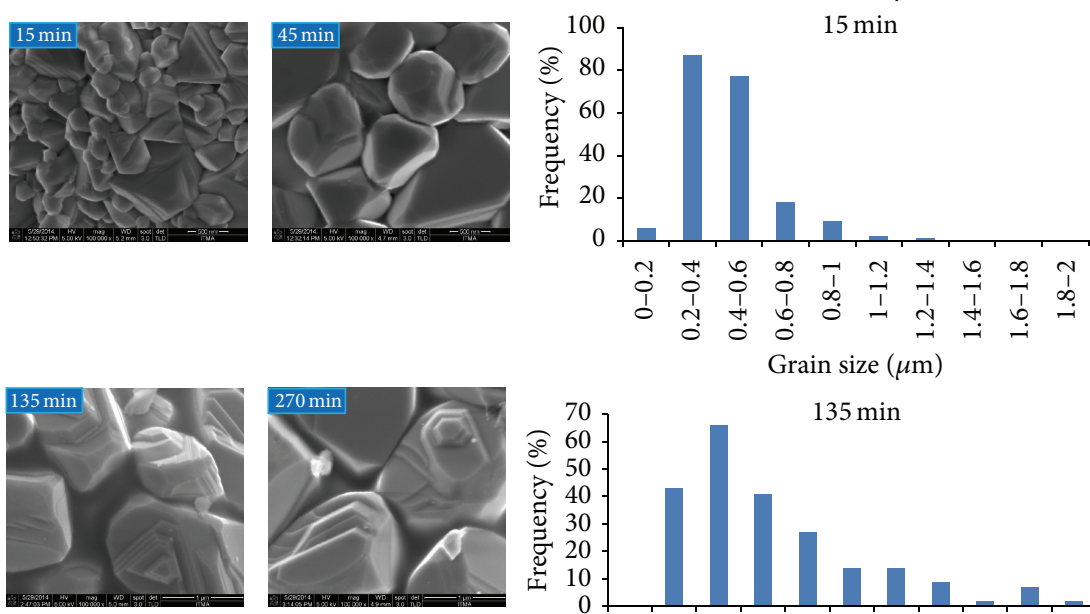

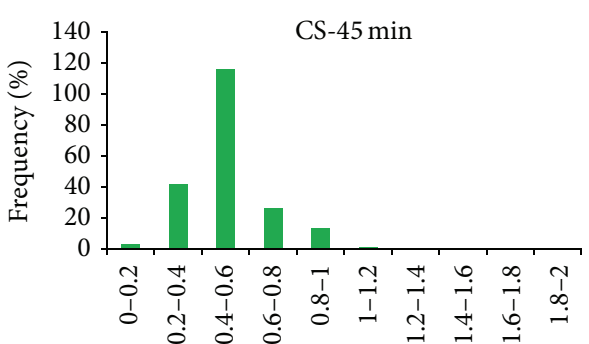

Grain size $(\mu \mathrm{m})$
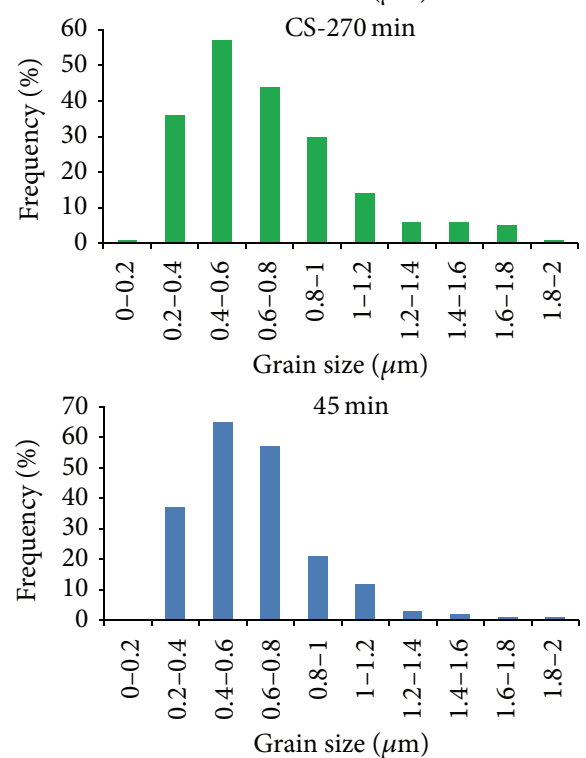

$270 \mathrm{~min}$

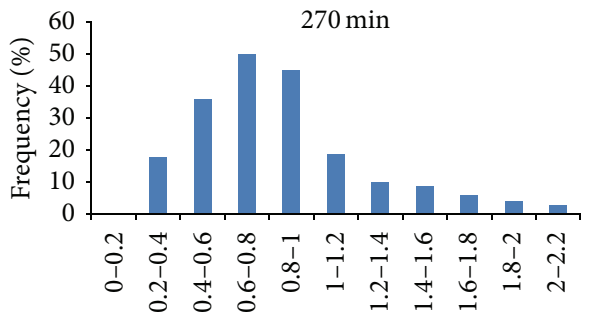

Grain size $(\mu \mathrm{m})$

FIGURE 2: FeSEM images of the two types of samples sintered at different times with their corresponding grain size distribution histograms.

TABLE 1: Structural, electrical, and magnetic characteristics of the two types of samples at different sintering times.

\begin{tabular}{lcccccccc}
\hline $\begin{array}{l}\text { Sintering } \\
\text { time }(\mathrm{min})\end{array}$ & $\begin{array}{c}\text { Average grain } \\
\text { size }(\mu \mathrm{m})\end{array}$ & $B_{S}$ (Gauss) & $B_{r}$ (Gauss) & $\begin{array}{c}H_{C}(\mathrm{Oe}), \\
(M-H \text { curve })\end{array}$ & $\begin{array}{c}\text { Density } \\
\left(\mathrm{g} / \mathrm{cm}^{3}\right)\end{array}$ & $\begin{array}{c}\text { Resistivity } \\
(\Omega \cdot \mathrm{cm})\end{array}$ & $\begin{array}{c}M_{S}(\mathrm{emu} / \mathrm{g}) \\
(M-H \mathrm{curve})\end{array}$ \\
\hline 0 & & - & - & - & 4.61 & - & - & - \\
15 & 0.461 & 883.2 & 421.3 & 3.43 & 5.25 & $9.7 \times 10^{10}$ & 52.29 & 21.43 \\
45 & 0.642 & 999.4 & 447.9 & 3.94 & 5.36 & $8.4 \times 10^{10}$ & 56.30 & 31 \\
135 & 0.733 & 1023 & 503.5 & 6.19 & 5.39 & $6.2 \times 10^{10}$ & 58.29 & 33.23 \\
270 & 0.806 & 1052 & 542.8 & 4.21 & 5.46 & $9.1 \times 10^{9}$ & 59.11 & 32.9 \\
CS-0 & - & - & - & - & 4.01 & - & - & - \\
CS15 & 0.350 & 396.3 & 135.5 & 7.53 & 4.11 & $8.7 \times 10^{11}$ & 51.66 & 27.67 \\
CS-45 & 0.519 & 421 & 149.5 & 8.96 & 4.32 & $6.5 \times 10^{11}$ & 53.63 & 31.44 \\
CS-135 & 0.641 & 630.3 & 279.6 & 9.06 & 4.87 & $2.9 \times 10^{11}$ & 57.76 & 32.02 \\
CS-270 & 0.696 & 597.5 & 365.3 & 17.61 & 5.28 & $1.1 \times 10^{11}$ & 54.90 & 33.63 \\
\hline
\end{tabular}



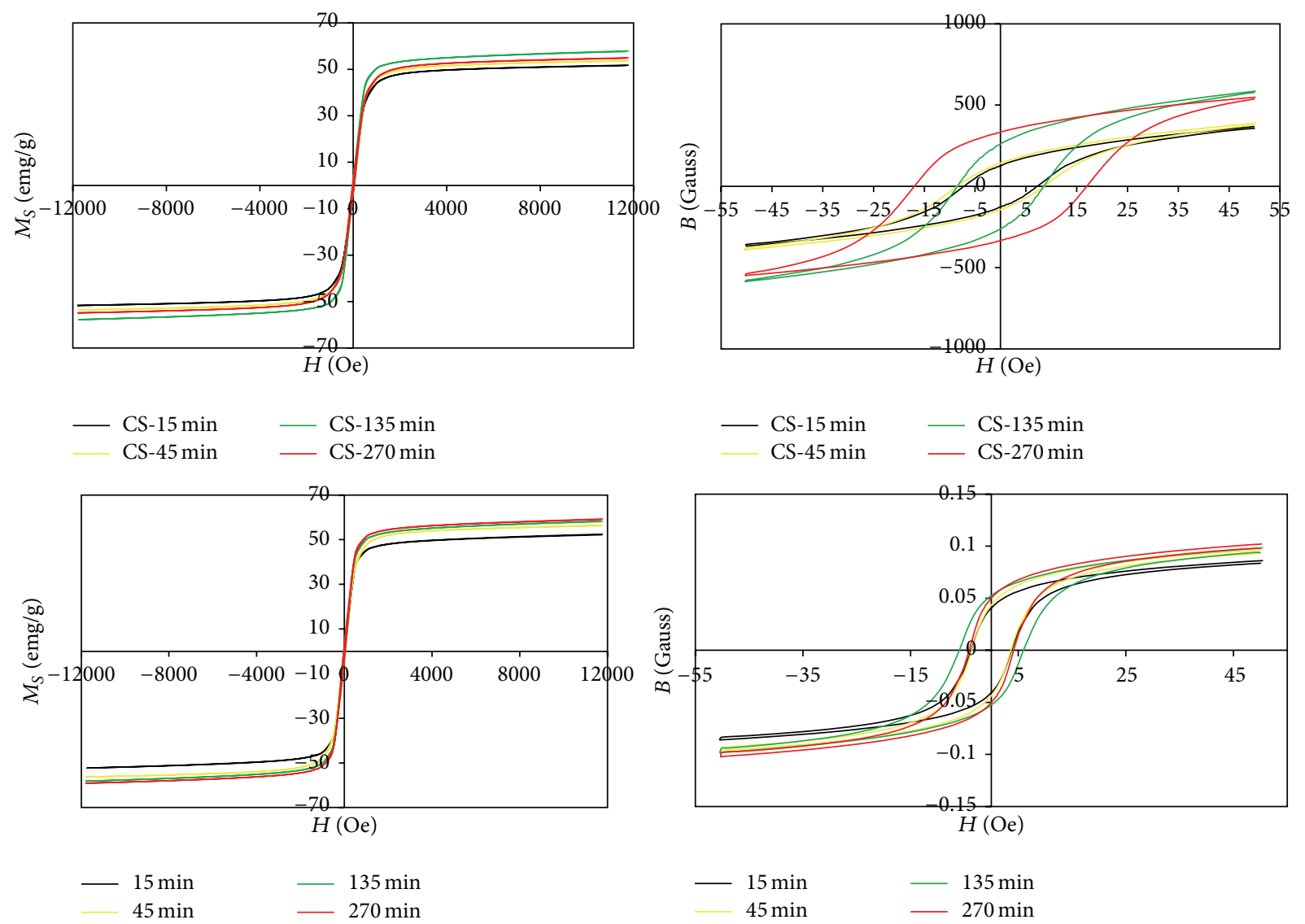

FIGURE 3: Room temperature hysteresis loops $(B-H$ and $M-H)$ for the two types of samples at different sintering times.

of $0.461 \mu \mathrm{m}$. Further sintering at $1200^{\circ} \mathrm{C}$ for $270 \mathrm{~min}$ led to a dominant grain size distribution of 0.4 to $1.2 \mu \mathrm{m}$, with its average being $0.806 \mu \mathrm{m}$. Based on the grain sizes obtained, it may be concluded that the additives, even at such small amounts as $0.12 \%$, significantly hindered grain growth and improved the microstructure of the samples. $\mathrm{SiO}_{2}$ and $\mathrm{CaO}$ ions segregate to the grain boundaries to inhibit grain growth. Furthermore, $\mathrm{SiO}_{2}$ leads to improved microstructure although the additive's critical amount is yet to be determined $[10,11]$.

The $B-H$ and $M-H$ hysteresis loops in Figure 3 and the results in Table 1 indicate that the values of $B_{S}$ and $M_{S}$ in the additive-free samples continuously increased with both grain growth and increasing sintering time. This is because the samples gained a greater domain wall area as a result of increasing grain size so that they easily moved and lined up in the direction of the externally applied field.

A similar trend was observed in $B_{r}$ values. Coercivity $\left(H_{C}\right)$ variation can be explained by the microstructure features of grain size and anisotropy. In other words, $H_{C}$ increased from 3.43 (for $B-H$ curve) to 21.43 Oe (for $M-H$ curve) to reach its maximum values of about 6.19 and 32.9 Oe, respectively, with increasing sintering time to $135 \mathrm{~min}$. This may be attributed to the grain growth obeying Herzer's random anisotropy model $\left(H_{C} \alpha D^{6}\right)$. However, the decreasing coercivity after $135 \mathrm{~min}$ of sintering can be attributed to the release of lattice defects and to the stress induced during the milling process at longer sintering durations, which obviously follows the classical model $\left(H_{C} \alpha 1 / d\right)$ [12].

Resistivity of the additive-free samples exhibited an inverse proportion to grain growth while density showed a direct proportion. Regarding the density, it can be said that grain growth gave rise to porosity segregated to grain boundaries with increasing sintering time such that highdensity bulk samples were obtained [13]. In the case of resistivity, grain growth was not high at a low sintering time of $15 \mathrm{~min}$ compared to the longer duration of $270 \mathrm{~min}$; hence, the grains had a higher surface-to-volume ratio. This caused more grains to be isolated by grain boundaries acting as barriers to the electron flow [14]. Consequently, resistivity would tend to reduce with both grain growth and the reduced grain-to-grain surface contact area. This agrees with Arrhenius equation (i.e., $\rho=\rho_{0} \exp (E / K T)$ ), showing a semiconducting behavior by the samples.

The additive-containing samples not only exhibited a significantly degenerating magnetic behavior as evidenced by their lower $B_{r}, B_{S}$, and $M_{S}$ values but also did not present a regular grain size variation. The variation of $B_{S}$ and $M_{S}$ with sintering time for both types of the samples is shown in Figure 4. Increasing sintering time from 15 to $135 \mathrm{~min}$ led to increased $B_{S}$ and $M_{S}$ values with grain growth, which rose from 369.3 gauss and $51.66 \mathrm{emu} / \mathrm{g}$ to their maximum 

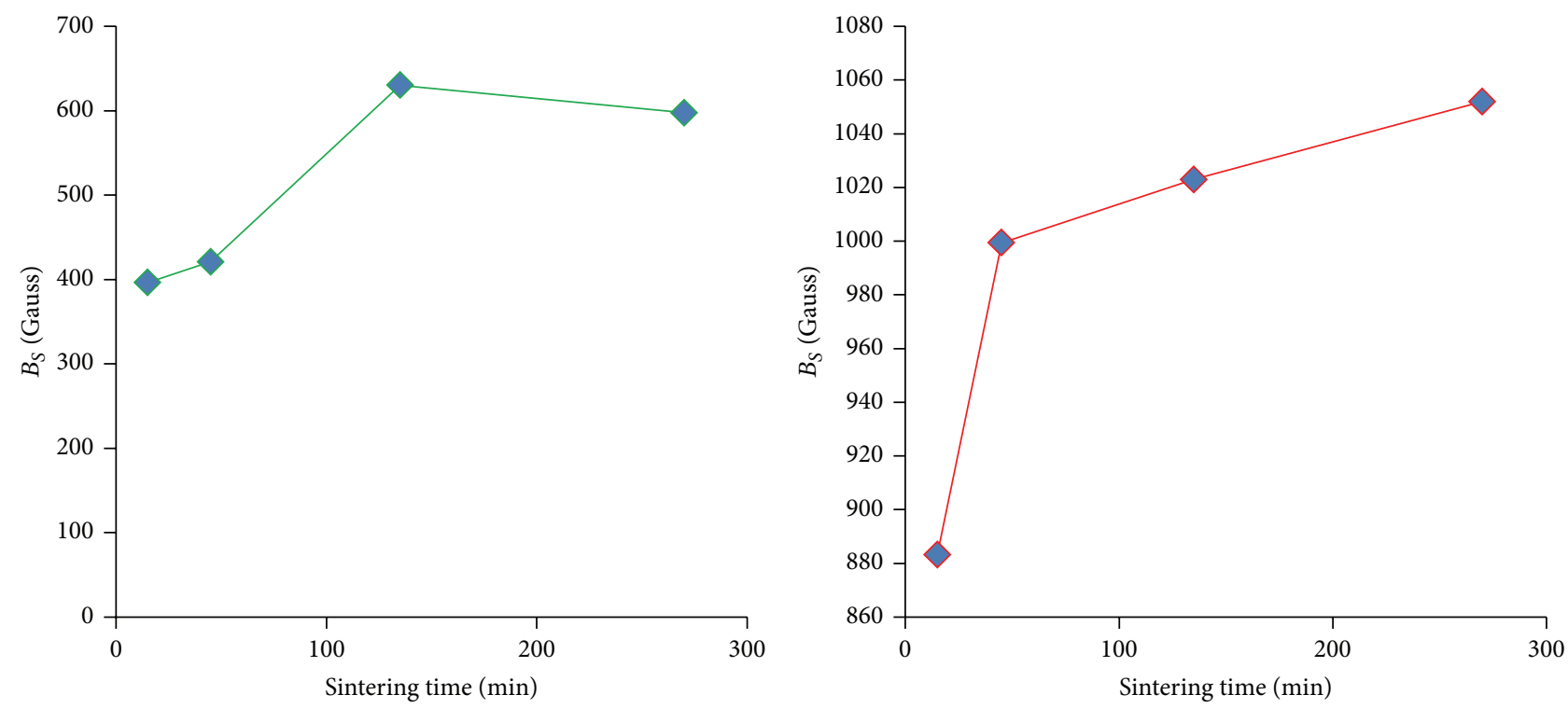

$\rightarrow \bullet \mathrm{Ni}-\mathrm{Zn}$ ferrite samples with additives

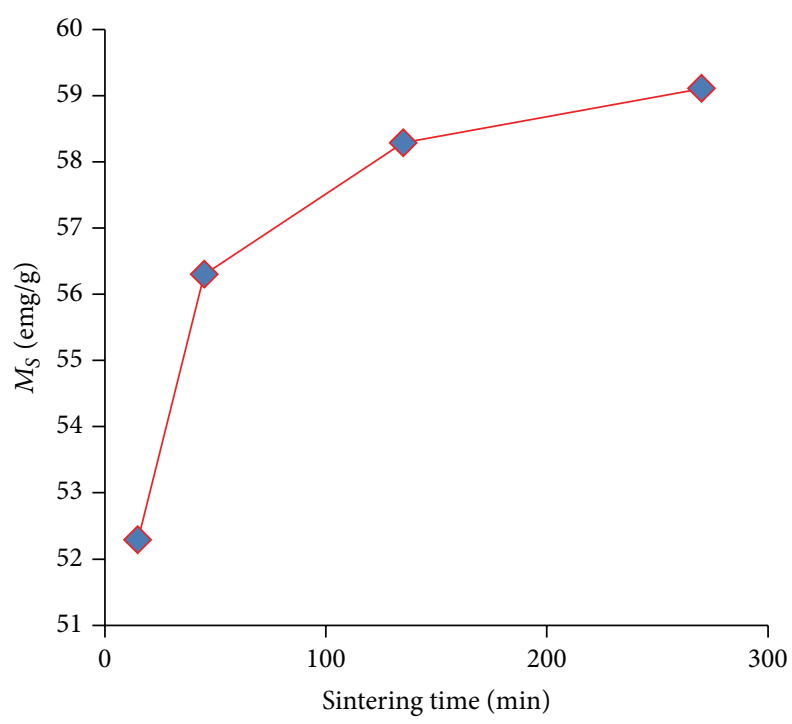

$\_\mathrm{Ni}-\mathrm{Zn}$ ferrite samples without additives

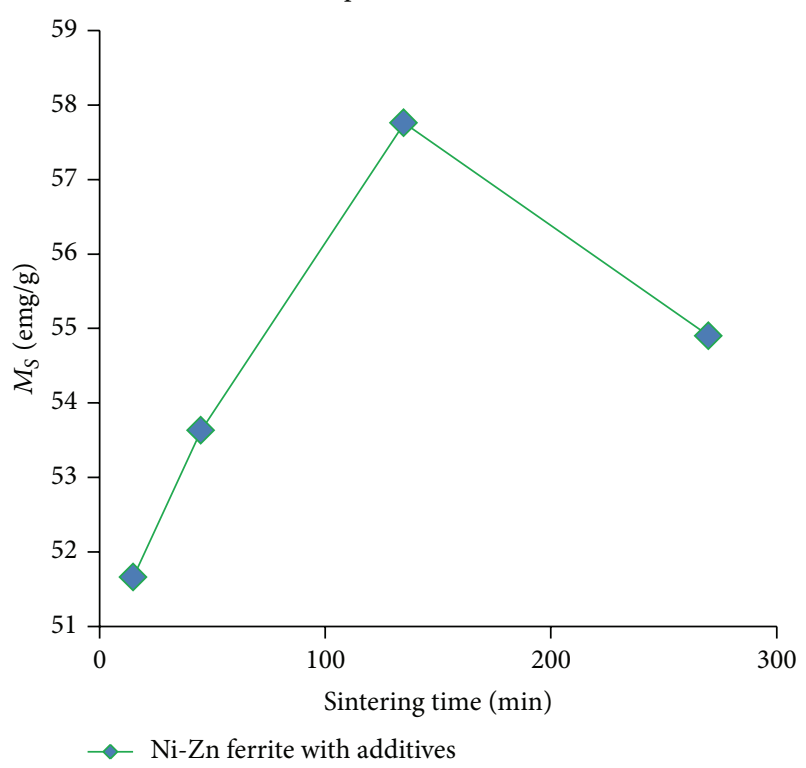

FIgURE 4: Variation of $M_{S}$ and $B_{S}$ with sintering time.

values of 630.3 gauss and $57.76 \mathrm{emu} / \mathrm{g}$, respectively. This may be explained along the same lines as above. In other words, the negligible reduction in the values after sintering from $135 \mathrm{~min}$ to $270 \mathrm{~min}$ and their subsequent fall to 597.5 gauss and $54.90 \mathrm{emu} / \mathrm{g}$ may be related to the slight zinc loss from the sample.

These same samples exhibited a higher coercivity $\left(H_{C}\right)$ than their additive-free counterparts. This can be attributed to their smaller grain size. This is consistent with previous reports which stated that soft ferrite with a smaller grain size had a higher $H_{C}$ than that with a bigger grain size [15].

By increasing sintering time, however, the resistivity decreased in the additive-containing samples; they presented higher values as compared to the additive-free ones (Table 1 ). This is because of the smaller grain size and the greater homogeneity of the former. Since a greater quantity of $\mathrm{Fe}^{2+}$ probably forms due to zinc loss, which increases conductivity due to the hopping mechanism [8], it may be concluded that $\mathrm{SiO}_{2}$ and $\mathrm{CaO}$ prevent zinc loss and, thereby, give rise to a higher resistivity. This is clear from the comparison of resistivity values for the two types of samples. Density, however, not only was lower in the additive-containing samples, but also decreased with increasing sintering time and grain growth. This can be explained by the distribution of cations. It is believed that $\mathrm{Zn}$ cations are heavier than $\mathrm{Ni}, \mathrm{Si}$, and $\mathrm{Ca}$ cations. In the presence of the additives, they would, therefore, replace $\mathrm{Zn}$ positions at tetrahedral sites resulting in the reduced density of the samples. Furthermore, zinc is less resistant than the above-mentioned cations, which further contributes to the reduced resistivity. 


\section{Conclusion}

Mechanically alloying with subsequent heat treatment is a desirable technique to produce single phase $\mathrm{Ni}_{0.36} \mathrm{Zn}_{0.64} \mathrm{Fe}_{2} \mathrm{O}_{4}$ ferrite and its spinel phase with additives, that is, $\mathrm{SiO}_{2}$ and $\mathrm{CaO}$. Increasing sintering time gave rise to grain growth in both types of samples prepared while adding an amount of common oxides of $0.4 \mathrm{CaO}+0.8 \mathrm{SiO}_{2}$ as small as $0.12 \%$ was able to hinder grain growth and improve the microstructure. Adding oxides to $\mathrm{Ni}-\mathrm{Zn}$ ferrite also led to a remarkable increase in resistivity. The additives were also observed to prevent zinc loss at higher sintering times and temperatures but resulted in the degeneration of such magnetic properties as $B_{S}$ and $M_{S}$. It may, therefore, be stated that the purpose of using additives depends on the aims and applications.

\section{Conflict of Interests}

The authors declare that there is no conflict of interests regarding the publication of this paper.

\section{Acknowledgment}

The corresponding author would like to appreciate University Putra Malaysia Graduate Research Fellowship section for providing financial support for this work.

\section{References}

[1] J. Bera and P. K. Roy, "Effect of grain size on electromagnetic properties of $\mathrm{Ni}_{0.7} \mathrm{Zn}_{0.3} \mathrm{Fe}_{2} \mathrm{O}_{4}$ ferrite," Physica B: Condensed Matter, vol. 363, no. 1-4, pp. 128-132, 2005.

[2] K. Kulikowski, "Soft magnetic ferrites-development or stagnation?" Journal of Magnetism and Magnetic Materials, vol. 41, no. 1-3, pp. 56-62, 1984.

[3] T. Jahanbin, M. Hashim, and K. Amin Mantori, "Comparative studies on the structure and electromagnetic properties of $\mathrm{Ni}-\mathrm{Zn}$ ferrites prepared via co-precipitation and conventional ceramic processing routes," Journal of Magnetism and Magnetic Materials, vol. 322, no. 18, pp. 2684-2689, 2010.

[4] A. T. Raghavender, N. Biliškov, and Ž. Skoko, "XRD and IR analysis of nanocrystalline Ni-Zn ferrite synthesized by the sol-gel method," Materials Letters, vol. 65, no. 4, pp. 677-680, 2011.

[5] K. Konds, T. Chiba, E. Otsuki, and S. Yamada, in Proceedings of 8th International Conference on Ferrite (ICF '00), vol. 8, p. 396, 2000.

[6] A. Hajalilou, M. Hashim, and H. M. Kamari, "Structure and magnetic properties of $\mathrm{Ni}_{0.64} \mathrm{Zn}_{0.36} \mathrm{Fe}_{2} \mathrm{O}_{4}$ nanoparticles synthesized by high-energy milling and subsequent heat treatment," Journal of Materials Science: Materials in Electronics, 2014.

[7] A. C. F. M. Costa, E. Tortella, M. R. Morelli, and R. H. G. A. Kiminami, "Synthesis, micro-structure and magnetic properties of Ni-Zn ferrites," Journal of Magnetism and Magnetic Materials, vol. 256, pp. 174-182, 2003.

[8] T. J. Shindea, A. B. Gadkari, and P. N. Vasambekar, "DC resistivity of Ni-Zn ferrites prepared by oxalate precipitation method," Materials Chemistry and Physics, vol. 111, no. 1, pp. 87-91, 2008.

[9] Y. Bando, T. Kato, Y. Ikeda, and T. Takada, "Phase equilibria in the system calcium oxide-manganese zinc ferrite," Bulletin of the Institute for Chemical Research, Kyoto University, vol. 46, pp. 289-294, 1968.

[10] G. C. Jain, B. K. Das, and S. Kumari, "ON the origin of core losses in a manganese Zinc ferrite with appreciable Silica content," Journal of Applied Physics, vol. 49, no. 5, pp. 2894-2897, 1978.

[11] F. J. C. M. Toolenaar and M. T. J. Verhees, "Reactive sintering of zinc ferrite," Journal of Materials Science, vol. 23, no. 3, pp. 856-861, 1988.

[12] T. D. Shen, R. B. Schwarz, and J. D. Thompson, "Soft magnetism in mechanically alloyed nanocrystalline materials," Physical Review B, vol. 72, pp. 14431-14438, 2005.

[13] S. L. Kang, Sintering: Densification, Grain Growth and Microstructure, Elsevier Butterworth-Heinemann, Burlington, Mass, USA, 2005.

[14] W. D. Kingery, H. K. Bowen, and D. R. Uhlmann, Introduction to Ceramics, John Wiley \& Sons, New York, NY, USA, 2nd edition, 1976.

[15] M. Pal, P. Brahma, D. Chakravorty, D. Bhattacharyya, and H. S. Maiti, "Nanocrystalline nickel-zinc ferrite prepared by the glass-ceramic route," Journal of Magnetism and Magnetic Materials, vol. 164, no. 1-2, pp. 256-260, 1996. 

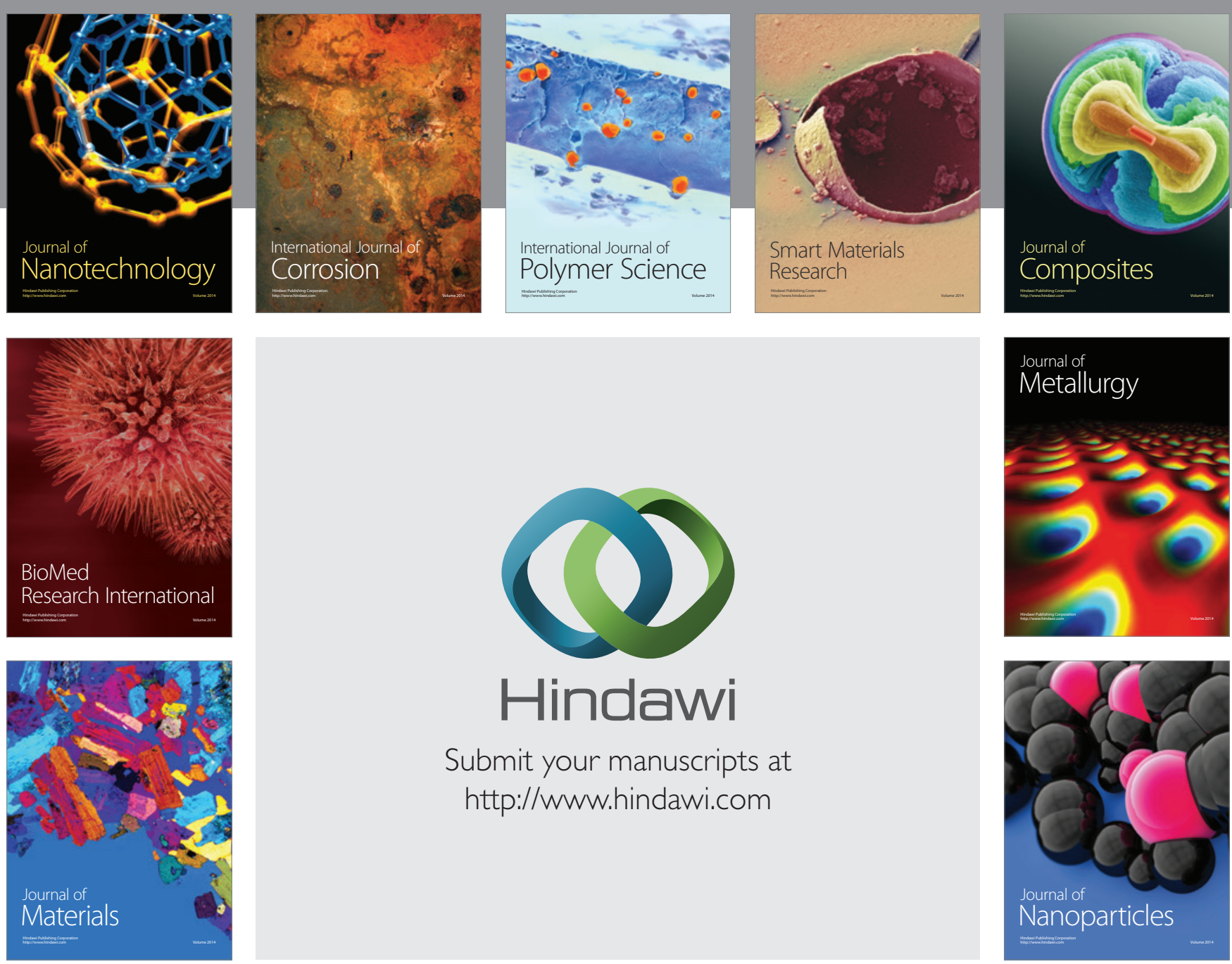

Submit your manuscripts at http://www.hindawi.com
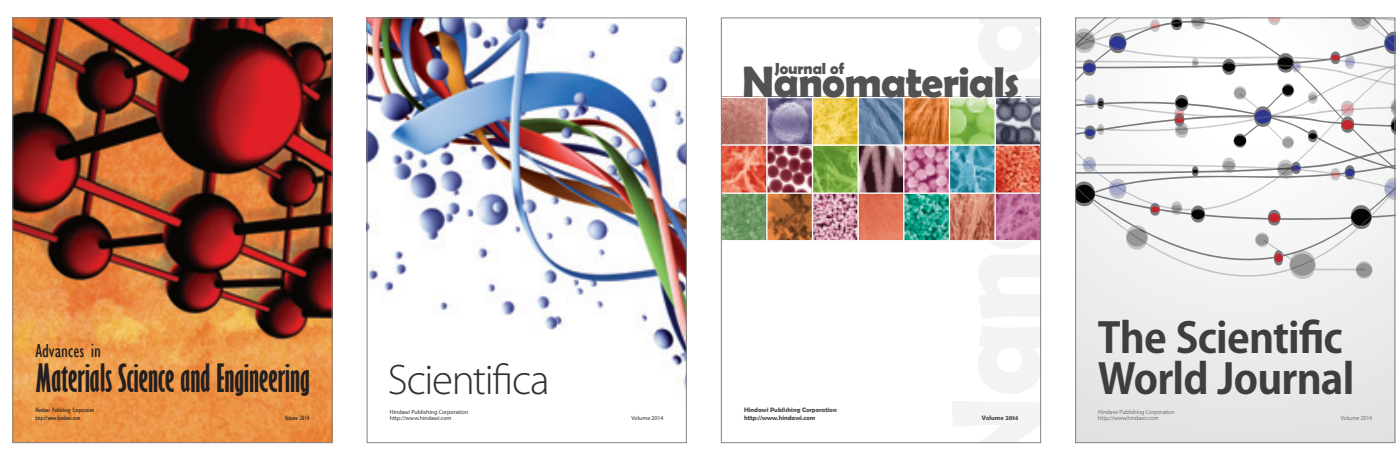

\section{The Scientific World Journal}
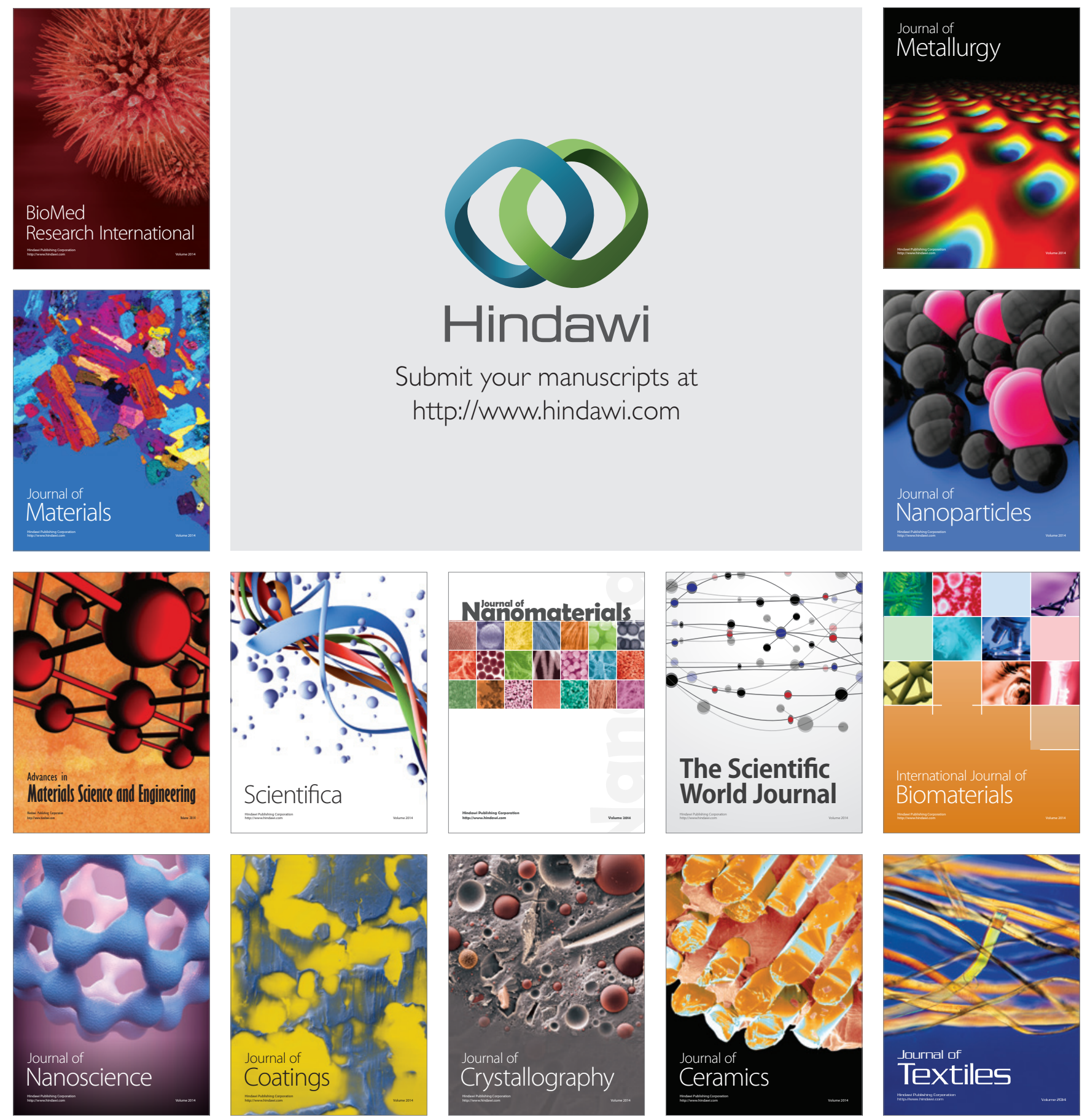